\title{
Prognosis of the Newborns with Congenital Heart Diseases
}

Akbar Molaei $^{1 *}$, Gholamreza Asadi², Maryam Khoshbakht ${ }^{2}$

1. Pediatric interventional cardiologist, cardiovascular research center, Tabriz University of medical sciences (TBUMS), Tabriz, Iran

2. Faculty of medicine, Azad university of Tabriz, Tabriz, Iran

\begin{abstract}
Background: Congenital heart disease $(\mathrm{CHD})$ is defined as problems affecting the heart of the fetus. According to previous studies, the incidence rate varies from 4-12 in 1000 live births. This study aimed to evaluate the demographic characteristics, clinical presentations, and findings that have impact on the prognosis of newborns hospitalized in Tabriz children Hospital, northwest of Iran. Methods: This cross-sectional study was conducted on 82 neonates with CHD admitted in Tabriz children Hospital, northwest of Iran from December 2011 to December 2012. Demographic characteristics, main complaints, symptoms, clinical presentations, associated anomalies, diagnoses, and also the correlation between the treatment process and mortality were evaluated. All data were analyzed using SPSS ${ }^{\text {TM }}$ version 16 statistical software. Results: A total of 82 neonates with CHD were enrolled. The mean age and birth weight were 8.54 days and 2828.17 grams, respectively. The most common chief complaint was respiratory distress (58 cases, $70.73 \%$ ). The most common diagnosis was d-transposition of great arteries and the most frequent therapeutic procedure was medical therapy in combination with mechanical ventilation (31 cases, $37.8 \%$ ). 10 neonates (12.1\%) had complications while seizure was the most common complication of the study (4 case, 4.87\%). Of 82 newborns in this study, 30 patients (36.6\%) died of which 13 cases (43.33\%) had DTGA; the most common therapeutic procedure was mechanical ventilation plus medical therapy which was performed in 22 patients (73.33\%). In our study, no significant correlation could be observed between age, sex or weight of neonates and final outcome. Conclusion: Mortality of neonates with critical CHD is high. Also, the neonates treated with more invasive methods have higher mortality rates. It is obvious that both early detection and timely management affect ultimate prognosis of these patients. Hence, prenatal (fetal echocardiography) and postnatal (pulse oximetry and echocardiography) diagnostic evaluations and instituting appropriate referral system are crucial. Furthermore, establishment of neonatal and pediatric intensive care and pediatric cardiac, cardiac surgery and catheterization laboratory units in the same tertiary center is suggested.
\end{abstract}

Keywords: Prognosis; Congenital heart disease; Newborn

\section{Corresponding author:}

Akbar Molaie, MD

Pediatric interventional cardiologist, Cardiovascular research center, Tabriz University of medical sciences (TBUMS), Tabriz, Iran

Receive date: 2015-03-12| Accept date: 2014-04-26| Publish date: 2015-05-03

DOI: 10.7575/aiac.abcmed.15.03.03.08

\section{A. I}




\section{Introduction}

Congenital heart disease (CHD) refers to structural and functional problems of the heart which occur due to abnormal heart development. Being associated with substantial noninfectious perinatal morbidity and mortality, CHD is one of the most common congenital malformations among newborns. With an estimated incidence of 4-12/1000 (0.4$1.2 \%$ ) of live births, CHD accounts for $4 \%$ of all neonatal deaths; $50 \%$ of all deaths in patients with CHD occur during the first year of life.1-10

Despite remarkable progresses in medical sciences, the major cause of CHD is not wellknown yet. However, previous studies demonstrated that both genetic and environmental factors have significant impacts on CHD pathogenesis.8-11 CHD could lead to a wide range of defects.12 Administration of some medicines such as anticonvulsants, lithium or progesterone during pregnancy may be blamed for its occurrence. Ventricular Septal Defect (VSD) is the most common congenital heart anomaly accounting for approximately $30-40 \%$ of CHDs.13 Substantial advances have been made in diagnosis (even before birth), treatment (medical, transcatheter, and surgical), and care methods among these patients in developed countries. These factors have led to significantly improved longevity, lifestyle and quality of life among these patients.14

Although the prevention of CHD is beyond the capability of current medical sciences (except for the ability of controlling the effective factors such as consanguinity, drugs consumption and other teratogenic supplements during the pregnancy), progress in treatment and care methods has been associated with hopeful results.

A wide range of reported mortality rates could be found in the literature. Although there are few studies on the management of $\mathrm{CHD}$ in children with low birth weight, there is not any report on the incidence of CHD in children with low birth weight; however, the incidence of these diseases are much higher in preterm infants. Thanks to more appropriate obstetric care and more available prenatal diagnosis, prognosis of preterm infants has been improved compared to last decades. Thus, it is likely that these factors may affect the incidence of mortality in children with CHD.15

Prematurity and birth weight of less than $2500 \mathrm{gr}$ are the risk factors for increasing hospital mortality. Optimal timing and type of intervention are controversial in premature infants with complex congenital heart disease. The mortality rate is almost $30 \%$ in premature children with very low birth weight.16 On the other hand, evaluating factors with the ability of affecting the preoperative status and side effects of surgery would be useful in improving the long-term prognosis. Considering the large number of hospitalized patients in pediatric hospitals and the significant morbidity and mortality in neonates with $\mathrm{CHD}$, we decided to investigate causes and risk factors for mortality in these neonates and evaluate the efficacy of the therapeutic procedures in the neonatal intensive care unit (NICU) on prognosis of newborns with CHD.

\section{Material \& methods}

In this cross-sectional retrospective study, lasting for 12 month, medical records of 82 newborns with CHD admitted in NICU of Tabriz children hospital, northwest of Iran were reviewed. All required information was obtained from hospital records and all patients' information remained confidential. This study was approved by local medical ethical committee of Tabriz University of medical sciences.

Medical records of patients were reviewed and all data related to prenatal and postnatal 
findings, also any complications having required further intervention during the treatment courses and those associated with the outcome and prognosis of patients were collected using the designed checklists. Also, clinical symptoms, diagnosis, complications and patients' health status at discharge from the hospital were evaluated. Studied variables were: age, sex, weight, chief complaint, associated symptoms, associated disease, complications, final diagnosis, treatment methods and final status of the patients. Measurements were expressed as mean \pm standard deviation (SD), frequency and percentage. Chi square test and Fishers' exact test were used to compare the study variables. The obtained data were analyzed using SPSS ${ }^{\text {TM }}$ version 16 statistical software (SPSS Inc., Chicago, IL, USA). In this study, $\mathrm{P}<0.05$ was considered statistically significant.

\section{Results}

Of 82 cases, 51 patients (62\%) were male. The mean age and weight of the patients were 8.54 days (range $=1-30$ days) and 2828.17 gram (range=1350.00-4500.00 gr), respectively.

In this study, the mean age at diagnosis in hospitalized patients was 8.54 days and the mean birth weight of patients was $2828.17 \mathrm{gr}$. Respiratory distress was the most common complaint in patients (58 patients, 70.7\%) and cyanosis was the second most common complaint (20 patients, 24.4\%). Mechanical ventilation combined by medical therapy was the most common treatment method used (31 patients, $37.8 \%)$. Also, 2 patients (2.43\%) were given interventional treatment, 29 cases (35.4\%) medical therapy only and 6 patients (7.3\%) were treated surgically. 13 patients (15.8\%) had coexisting diseases and 69 cases (84.1\%) had no coexisting diseases. In addition, multiple congenital anomalies were the most common associated anomaly in (3 patients, $3.7 \%)$. Down syndrome was observed in 2 patients $(2.4 \%) .12 .1 \%$ of the patients (10 cases) experienced complications; seizure was observed in 4 patients $(4.87 \%)$ as the most common complication .2 patients (2.4\%) experienced pneumothorax and the other 2 (2.4\%) cases experienced Pneumonia. Moreover, 1 patient (1.2\%) had gastrointestinal bleeding and 1 patient (1.2\%) had pleural effusion. Of 82 newborns in this study, 30 patients (36.6\%) died of which 13 cases (43.33\%) had DTGA.

Respiratory distress was the most common complaint among the patients (Table-1). Medical therapy and mechanical ventilation plus medical therapy were the most commonly administered therapeutic methods (Table-1).

There was no coexisting disease in 69 (84.1\%) of patients; esophageal atresia (EA) was the most common associated disease in (8 patients, 9.75\%) (Table-1). Regarding the associated complications with CHD, our study revealed that $72(87.8 \%)$ patients had no associated complications; meanwhile, seizure was the most common associated complication in $4(4.87 \%)$ patients (Table- 1$)$.

Among the treatment methods, the only significant association was observed between the medical therapy method and the final outcome of the discharged patients $(P<0.001$, $\mathrm{R}=0.317$ ). Also, the combination of medical therapy and mechanical ventilation was of significant correlation with the mortality ( $P<0.001, R=0.442$, Table 3).

Regarding the final status of the patients, 13 $(15.85 \%)$ cases were clinically followed up, 39 (47.56\%) cases were medically followed up and 30 (36.58\%) cases died.

\section{Discussion}

Over the past $10-15$ years, the medical world has been witnessing dramatic developments in diagnosis and treatment (or mitigation) of $\mathrm{CHD}$ in newborns. Advanced diagnostic methods such as echocardiography have played a major 


\begin{tabular}{|c|c|}
\hline Parameter & Patients $(n=82)$ \\
\hline \multicolumn{2}{|l|}{ Main complaints: } \\
\hline Respiratory distress & $58(70.7 \%)$ \\
\hline Cyanosis & $20(24.4 \%)$ \\
\hline poor feeding & $1(1.2 \%)$ \\
\hline oliguria & $1(1.2 \%)$ \\
\hline palpitation & $2(2.4 \%)$ \\
\hline \multicolumn{2}{|l|}{ Treatment method: } \\
\hline Medical therapy & $29(35.4 \%)$ \\
\hline Transcatheter Intervention & $2(2.4 \%)$ \\
\hline surgury & $6(7.3 \%)$ \\
\hline clinical follow up & $6(7.3 \%)$ \\
\hline mechanical ventilation + Medical therapy & $31(37.8 \%)$ \\
\hline mechanical ventilation + surgery & $8(9.8 \%)$ \\
\hline \multicolumn{2}{|l|}{ Associated diseases with CHD: } \\
\hline Without any diseases & 69 (84.1\%) \\
\hline Down syndrome:D.S & $2(2.4 \%)$ \\
\hline Cleft palate:C.P & $1(1.2 \%)$ \\
\hline Bile duct atresia:B.D.A & $1(1.2 \%)$ \\
\hline Multiorgan anomaly: MOA & $3(3.7 \%)$ \\
\hline Choanal atresia:C.A & $1(1.2 \%)$ \\
\hline Esophageal atresia:EA & $8(9.75 \%)$ \\
\hline Intestinal atresia: IA & $2(2.4 \%)$ \\
\hline $\mathrm{IA}+\mathrm{EA}$ & $1(1.2 \%)$ \\
\hline \multicolumn{2}{|l|}{ Associated complications with CHD: } \\
\hline Without any complication & $72(87.8 \%)$ \\
\hline Seizures & $4(4.87 \%)$ \\
\hline gastrointestinal(GI)Bleeding & $1(1.2 \%)$ \\
\hline Pneumothorax & $2(2.4 \%)$ \\
\hline Pneumonia & $2(2.4 \%)$ \\
\hline Pleural effusion & $1(1.2 \%)$ \\
\hline
\end{tabular}

Table 1: frequency of main complaints, treatment methods and associated diseases and complications with CHD

role in this regard. In addition, sophisticated surgical techniques have made it possible to complete treatment or mitigation in infants with $\mathrm{CHD}$ weighing even less than $1.5-2 \mathrm{Kg} .17$

In a study by Henry et al. on 180 patients, the authors reported that 37 cases (21\%) died at the hospital. Mechanical ventilation plus medical therapy were reported as one of the associated risk factors for mortality.15 In the current study, of 82 patients $36.6 \%$ (30 cases) died and of 31 patients treated by mechanical ventilation plus medical therapy, 22 patients
(70.96\%) died. Our results about the mortality and the requirement for mechanical ventilation are in line with the results of previous studies.

Kecskes et al. studied 47 infants with congenital heart disease; VSD and coarctation of aorta were the most common diagnoses in their study. Death due to congenital heart disease was reported in $32 \%$ of the cases with coarctation of aorta having the highest mortality rate (62\%).14

Similarly, in our study the mortality rate was $36.6 \%$ (30 cases); while, DTGA was the most 


\begin{tabular}{|c|c|}
\hline Final diagnosis & Patients $(n=82)$ \\
\hline d-transposition of the great arteries:DTGA & $20(24.4 \%)$ \\
\hline coarctation of the aorta: $\mathrm{COA}$ & $2(2.4 \%)$ \\
\hline ADS+PDA & $11(13.4 \%)$ \\
\hline patent ductus arteriosus: PDA & $3(3.7 \%)$ \\
\hline atrial septal defect:ASD & $3(3.7 \%)$ \\
\hline ventricular septal defect:VSD & $1(1.2 \%)$ \\
\hline $\begin{array}{c}\text { pulmonary hypertention }(\mathrm{PH})+\text { Mitral Supravalvular } \\
\text { ring }\end{array}$ & $1(1.2 \%)$ \\
\hline hypoplastic left heart syndrome:HLHS & $1(1.2 \%)$ \\
\hline COA+VSD & $2(2.4 \%)$ \\
\hline Pulmonary Atresia +Tricuspid Atresia +PDA & $1(1.2 \%)$ \\
\hline COA+PDA+ Server aortic valve stenosis(AS) & $1(1.2 \%)$ \\
\hline VSD+PDA & $5(6.09 \%)$ \\
\hline Sever AS & $1(1.2 \%)$ \\
\hline COA+ASD & $1(1.2 \%)$ \\
\hline DTGA+ single ventricle & $1(1.2 \%)$ \\
\hline PDA+ Pulmonary Atresia & $4(4.9 \%)$ \\
\hline \multicolumn{2}{|l|}{ Cardiomyopathy } \\
\hline Primary pulmonary hypertention(PPHN) & $1(1.2 \%)$ \\
\hline Cardiac Tumor & $1(1.2 \%)$ \\
\hline double outlet right ventricle(DORV) & $1(1.2 \%)$ \\
\hline \multicolumn{2}{|l|}{+ VSD+PH } \\
\hline Single Atrium + Single Ventricle $+\mathrm{PH}$ & $1(1.2 \%)$ \\
\hline pulmonary stenosis(PS)+dextrocardy & $1(1.2 \%)$ \\
\hline Pulmonary Atresia+ Intact ventricular septum & $1(1.2 \%)$ \\
\hline VSD+ASD & $3(3.7 \%)$ \\
\hline $\begin{array}{c}\text { COA+ Complete atrio-ventricular Canal } \\
\text { defect(CAVCD) }\end{array}$ & $1(1.2 \%)$ \\
\hline Complete AV Canal defect & $1(1.2 \%)$ \\
\hline COA+PDA & $4(4.9 \%)$ \\
\hline PS+ Single ventricle & $1(1.2 \%)$ \\
\hline Pulmonary Atresia +VSD & $2(2.4 \%)$ \\
\hline$C O A+V S D+A S D$ & $1(1.2 \%)$ \\
\hline$C O A+P D A+V S D$ & $1(1.2 \%)$ \\
\hline total anomalous pulmonary connection( TAPVC) & $1(1.2 \%)$ \\
\hline Idiopathic Dilated Cardiomyopathy & $2(2.4 \%)$ \\
\hline
\end{tabular}

Table 2: Final diagnosis of CHD

common diagnosis (20 cases, $24.4 \%$ ) and had the highest mortality rate $(43.33 \%)$.

In the studies by Brown et al. and Anagnostou et al., the mortality rates were $12 \%$ (of 286 patients) and 10\% (of 105 patients), respectively which were lower than the mortality rate in our study.16, 18 Moreover, in a study by Sawanta and colleagues, VSD (42.86\%) and ASD (25.71\%) were the most common CHDs, respectively. Also, VSD and TOF were more common in male patients and ASD was more common among female patients. Associated diseases were observed in $22.86 \%$ of patients with Down syndrome being the most common disease in this regard.19 In the 
present study, DTGA and ASD+PDA were the most common diseases in both groups and multiple congenital anomalies (3 Patients,

\begin{tabular}{lcc}
\multicolumn{1}{c}{ Parameter } & Patients (n=82) & Dead (n=30=36.58\%) \\
\hline Medical therapy & $29(35.4 \%)$ & $5(17.24 \%)$ \\
Transcatheter Interventional therapy & $2(2.4 \%)$ & $0(0 \%)$ \\
Surgery & $6(7.3 \%)$ & $1(16.6 \%)$ \\
Mechanical ventilation + medical therapy & $31(37.8 \%)$ & $22(70.96 \%)$ \\
Mechanical ventilation + surgery & $8(9.8 \%)$ & $2(25 \%)$ \\
Clinical follow up & $6(7.3 \%)$ & $0(0 \%)$ \\
\hline
\end{tabular}

Table 3: Mortality rate occurred by the used therapeutic methods

Padley and colleagues studied the final outcome of infants with congenital heart disease undergoing palliative or curative surgery in Australia during 5 years. The total mortality rate at hospital discharge and after 30 days of surgery was $1.9 \%$ and $1.3 \%$, respectively. 20 In our study, of 82 patients, 6 cases underwent surgery, 1 patient (16.6\%) died which is higher than previous studies. Alfieris et al. studied the final status of patients who underwent the surgery with DTGA diagnosis; in their study, of 96 patients who underwent surgery, the mortality rate of $0 \%$ was reported.21 Nevertheless, in our study of 20 patients with DTGA diagnosis, 6 cases were operated of which 3 cases (50\%) died, indicating the higher mortality rate.

In our study, no significant correlation between age, sex or weight of neonates and final outcome was observed.

\section{Conclusion}

Mortality rate of newborns with critical congenital heart disease is high, especially in those requiring invasive treatments such as mechanical ventilation or surgery. Mortality
3.7\%) was the most common associated anomaly. rate can be higher when the management is established with delay due to either delayed referral or diagnosis. Furthermore, separation of neonatal intensive care units from cardiac wards and cardiac surgery centers has significant effect on final outcome of these newborns. Hence, the following recommendations are suggested to improve the outcome of these patients:

1- Establishment of prenatal diagnostic procedures such as fetal echocardiography in high risk pregnancies

2- Routine upper and lower pulse oximetry in addition to precise physical examination before home discharge of neonates

3- Establishment of appropriate referral system for timely referral of these neonates to pediatric cardiologists

4- Establishment of neonatal intensive care units, pediatric cardiology catheterization laboratory, and pediatric cardiac surgery with trained and expert staff for timely and appropriate management of these patients in the same centers.

\section{References}

1. Cho SY, Oh JH, Lee JH, Lee JY, Lee SJ, Han JW, et al. Recent incidence of congenital heart disease in neonatal care unit of secondary medical center: a single center study. Korean J Pediatr. 2012;55(7):232-7. 
2. Liu Z, Li X, Li N, Li S, Deng K, Lin Y, et al. Association between maternal exposure to housing renovation and offspring with congenital heart disease: a multi-hospital case-control study. Environ Health. 2013;12:25.

3. Nikyar B, Sedehi M, Mirfazeli A, Qorbani M, Golalipour MJ. Prevalence and Pattern of Congenital Heart Disease among Neonates in Gorgan, Northern Iran (2007-2008). Iran J Pediatr. 2011;21(3):307-12.

4. Yun SW. Congenital heart disease in the newborn requiring early intervention. Korean J Pediatr. 2011;54(5):183191.

5. Ascher SB, Smith PB, Clark RH, Cohen-Wolkowiez M, Li JS, Watt K, et al. Sepsis in young infants with congenital heart disease. Early Hum Dev. 2012;88 Suppl 2:S92-7.

6. Racial differences by gestational age in neonatal deaths attributable to congenital heart defects-United States, 2003-2006. MMWR Morb Mortal Wkly Rep. 2010; 59:1208-11.

7. Boneva RS, Botto LD, Moore CA, Yang Q, Correa A, Erickson JD. Mortality associated with congenital heart defects in the United States: trends and racial disparities, 1979-1997. Circulation. 2001;103:2376-81.

8. Wichman CL, Moore KM, Lang TR, St Sauver JL, Heise RH Jr, Watson WJ. Congenital heart disease associated with selective serotonin reuptake inhibitor use during pregnancy. Mayo Clin Proc. 2009;84(1):23-7.

9. Richards AA, Garg V. Genetics of congenital heart disease. Curr Cardiol Rev. 2010;6(2):91-7.

10. Wang E, Sun S, Qiao B, Duan W, Huang G, An Y, et al. Identification of functional mutations in GATA4 in patients with congenital heart disease. PLoS One. 2013;8(4):e62138.

11. Billett J, Majeed A, Gatzoulis M, Cowie M. Trends in hospital admissions, in-hospital case fatality and population mortality from congenital heart disease in England, 1994 to 2004. Heart. 2008;94(3):342-8.

12. Harris IS. Management of Pregnancy in Patients with Congenital Heart Disease. Prog Cardiovasc Dis. 2011;53(4): 305-311.

13. Hoffman JI, Christanson R. Congenital heart disease in cohort of 19,502 birth with long - term follow -up. Am J Cardiol. 1978;42: $641-647$.

14. Kecskes Z, Cartwright D. Poor outcome of very low birthweight babies with serious congenital heart disease. Arch Dis Child Fetal Neonatal Ed. 2002;87(1): F31-F33.

15. Cheng HH, Almodovar MC, Laussen PC, Wypij D, Polito A, Brown DW, et al. Outcomes and risk factors for mortality in premature neonates with critical congenital heart disease. Pediatr Cardiol. 2011:32(8):1139-1146.

16. Brown KL, Ridout DA, Hoskote A, Verhulst L, Ricci M, Bull C. Delayed diagnosis of congenital heart disease worsens preoprative condition and outcome of surgery in neonates. Heart. 2006;92:1298-1302.

17. Haffman JIE, Kaplan S, Liberthson RR. Prevalence of congenital heart disease. Am Heart J, 2004;147, 425 -439.

18. Anagnostou K, Messenger L, Yates R, Kelsall W. Outcome of infants with prenatally diagnosed congenital heart disease delivered outside specialist paediatric cardiac centres. Arch Dis Child Fetal Neonatal Ed. 2013;98(3):F218-21.

19. Sawanta SP, Amin AS, Bhat M. Prevalence, pattern and outcome of congenital heart disease in Bhabha Atomic Research Centre Hospital, Mumbai. Indian J pediatr. 2013;80(4):286-291.

20. Padley JR, Cole AD, Pye VE, Chard RB, Nicholson IA, Jacobe S, et al. Five-year analysis of operative mortality and neonatal outcomes in congenital heart disease. Heart Lung Circ. 2011;20(7):460-7.

21. Alfieris GM, Dadlani GH, Vermilion RP, Smith FC, Gaum WE, Lipshultz SE, et al. Regional sharing optimizes arterial switch outcomes. Pediatric Cardiology. 2005;20:21-25. 